\title{
The Transformation and Storage of Solar Energy: Progress Towards Visible-Light Induced Water Splitting
}

\author{
Eric D. Cline and Stefan Bernhard*
}

\begin{abstract}
The sun is a plentiful source of clean, renewable power, and the direct conversion of solar to chemical energy is a desirable goal. The collective efforts of the Bernhard group to develop molecular catalytic systems for visible-light water splitting are reviewed. Combinatorial synthesis and high-throughput screening techniques enabled the development of a series of photosensitizers with a wide range of photophysical and electrochemical properties. Parallel evaluation of the iridium(III) photosensitizers in photocatalytic water reduction systems utilizing cobalt-, platinum-, or rhodium-based water reduction catalysts resulted in systems that exhibited more than 5000 turnovers with quantum yields of $34 \%$ and turnover frequencies of $500 \mathrm{hr}^{-1}$. For the complementary water oxidation system, the catalysts based on cyclometallated iridium complexes are robust and tunable, which allows for the rapid study of water oxidation reactions through targeted ligand modification.
\end{abstract}

Keywords: Electron transfer · Hydrogen $\cdot \operatorname{Ir}($ III) Photosensitizers $\cdot$ Photocatalysis · Water splitting

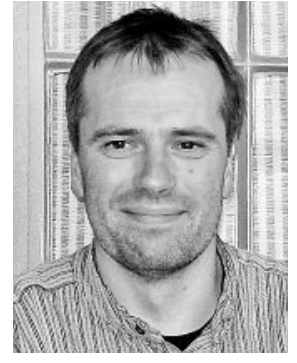

Following a laboratory technician apprenticeship with Chocolat Tobler, Stefan Bernhard studied chemical engineering at the Ingenieurschule Burgdorf. Further endeavors, under Professor Peter Belser at the Université de Fribourg, were awarded with a diploma and a $\mathrm{PhD}$ in chemistry. Stefan Bernhard's dissertation involved the synthesis of rigidly bridged dinuclear metal complexes for use in exploring photoinduced, intramolecular electron transfers. This primarily synthetic work was then complemented by a laser spectroscopy project at Los Alamos National Laboratory, which came in the form of a postdoctoral stay under the guidance of Dr. Jon Schoonover. A second postdoctoral assignment, this time in the Abruña group at Cornell University, involved electro- and photo-active coordination compounds and their application in organic light emitting devices, sensors, etc. Professor Stefan Bernhard's initial faculty appointment at Princeton University explored luminescent metal complexes for optoelectronic and solar conversion applications. The Bernhard group moved to Carnegie Mellon University in July, 2009.

\footnotetext{
${ }^{\star}$ Correspondence: Prof. S. Bernhard

Department of Chemistry

Carnegie Mellon University

4400 Fifth Avenue

Pittsburgh, PA 15213, USA

E-mail: bern@cmu.edu
}

\section{Introduction}

The current global energy demand of 16 TW is expected to increase $50 \%$ by $2030 .^{[1]}$ Meanwhile, with greenhouse-gas emissions reaching historic levels, convincing evidence is emerging on the effects of human activity, particularly the combustion of carbon-based fuels, on global warming and climate change. ${ }^{[2]}$ In order to satisfy humankind's insatiable hunger for energy in a sustainable manner, all forms of clean and renewable energy must be developed with urgency. ${ }^{[3]}$ Solar power shows the most promise of meeting future demand since the sun is a seemingly inexhaustible source of energy, providing the Earth with an annual solar insolation of 120,000 TW of electromagnetic radiation. However, for solar power to become a viable alternative to fossil fuels we must develop new methods for the cost-effective capture, conversion, and storage of solar energy. ${ }^{[4]}$ Hydrogen is a promising candidate as a medium for solar energy storage and a transportation fuel, although many monumental scientific advances must be made for this dream to become reality.

The goal of artificial photosynthesis is the development of efficient methods for the direct conversion of solar to chemical energy by converting water, one of Earth's most plentiful resources, into its higher energy components, $\mathrm{H}_{2}$ and $\mathrm{O}_{2}$, using visible light. Water splitting is a four-electron process that is thermodynamically uphill by $\Delta \mathrm{G} \approx 237$ $\mathrm{kJ} / \mathrm{mol}$, corresponding to a minimum energy of $1.23 \mathrm{eV}$ per electron (see Eqn. (1)). Assuming one photon per electron, any photon below $1008 \mathrm{~nm}$ wavelength can theoretically be used for the reaction, although in reality water is transparent to most of the solar spectrum and catalysts must be used to harvest the sunlight and convert it to chemical energy. Various strategies for solar water splitting using coupled photovoltaic electrolysis or semiconductor-based photoelectrochemical devices have been extensively reviewed elsewhere. ${ }^{[5]}$ The present review will focus on molecular photocatalytic systems that mimic photosynthesis utilizing transitionmetal catalysts.

Luminescent transition-metal complexes are very appealing for a variety of applications because synthetic modification allows manipulation of the photophysical and electrochemical properties, in order to tailor the properties of a complex to its specific application, e.g. organic light-emitting diodes (OLEDS), luminescent-based sensors, or photocatalysis. By designing catalysts for the oxidation or reduction of water that are capable of quenching the excited state by electron transfer, these luminophores can be implemented in photosynthetic systems. Designing a photocatalytic system for water splitting requires multielectron photochemistry and proton-coupled electron transfer with catalysts that are cheap and robust, a daunting challenge to say the least. The various coordinated efforts of the Bernhard research group to make rapid progress towards molecular catalytic systems for the visiblelight induced splitting of water are reviewed herein.

\section{Water Splitting System Design}

Although it appears to be a simple process, water photolysis (Eqn. (1)) is a 
complicated reaction that involves four proton-coupled electron transfers (PCET). Most schemes for molecular water-splitting systems involve multiple catalytic components, including a photosensitizer (PS), a water reduction catalyst (WRC), and a water oxidation catalyst (WOC). To develop the individual components that will eventually comprise a complete water splitting system, researchers simplify the task by separating the overall reaction into the individual oxidation and reduction half reactions (Eqns. (2) and (3)), replacing the other half reaction with an appropriate sacrificial oxidant or reductant, respectively. This is advantageous because the individual components can be studied and optimized for their specific task. Visiblelight induced water splitting has yet to be accomplished in homogeneous solution, although several rudimentary building blocks for such a system have emerged from research during the last thirty years using this approach to the problem.

$$
\begin{aligned}
& 2 \mathrm{H}_{2} \mathrm{O} \rightarrow \mathrm{O}_{2}+2 \mathrm{H}_{2} \\
& \Delta E^{0}=-1.23 \mathrm{~V}
\end{aligned}
$$

$$
\begin{aligned}
& 2 \mathrm{H}_{2} \mathrm{O} \rightarrow \mathrm{O}_{2}+4 \mathrm{H}^{+}+4 \mathrm{e}^{-} \\
& E^{0}=1.23 \mathrm{~V} \text { vs. NHE }
\end{aligned}
$$

$$
2 \mathrm{H}^{+}+2 \mathrm{e}^{-} \rightarrow \mathrm{H}_{2}
$$

$E^{0}=0.00 \mathrm{~V} v s . \mathrm{NHE}$

\section{Experimental Techniques for Rapid Discovery}

The complexity of artificial photosynthetic systems presents many challenges for researchers. While it is possible to study the physical properties of the individual components (e.g. photon absorption, excited state lifetimes, and redox potentials) and the fundamental processes of the system (e.g. electron transfer rates), it is difficult to understand and predict the effects of modifications of these parameters on the overall system performance. For this reason, the Bernhard lab has focused on developing techniques and equipment for rapid discovery of photocatalysts and related components through empirically driven research.

The use of combinatorial synthesis to synthesize diverse libraries of compounds, and high-throughput screening of the photophysical properties of these compounds, allows rapid development of novel luminophores. ${ }^{[6]}$ Furthermore, the experimental results from these studies have proven that density functional theory (DFT) can be used to accurately predict the effects of ligand substitutions on orbital energies. Future work will rely more heavily on theoretical predictions to direct the synthetic work.

To evaluate the catalyst systems and conditions for the water reduction and oxidation processes, a temperature controlled 16-well photoreactor was designed (Fig. 1). Each well is illuminated with an ultrabright LED (Luxeon V Dental Blue, 460 nm, 20 nm FWHM) with Fraen collimating optics that has been screened for uniform output $(500 \pm 50 \mathrm{~mW})$. The temperaturecontrolled reaction block accepts standard size EPA vials $(40 \mathrm{~mL})$ fitted with custom caps allowing for syringe addition and gas sampling. The caps are fitted with differential pressure transducers for real-time monitoring of the gas evolution kinetics in these reactions. A self-calibrating residual gas analyzer (Stanford Research Systems QMS200) enables rapid analysis of the reaction headspace at the endpoints for pressure curve normalization. A custom-built sample preparation robot helps to prepare complex arrays of photoreactions for studies of concentration and condition effects.

\section{Tailored Photocatalysts}

The essential feature of any photocatalytic system is the absorption of light by the PS to create an electronically excited state, with a threshold wavelength for excitation. The excited state (PS*) has characteristic energies associated with the lowest and highest singularly occupied molecular orbital (LSOMO and HSOMO) that can be exploited for energy conversion schemes, as illustrated in Fig. 2. In the reductive quenching pathway the WOC is oxidized by an electron transfer to the LSOMO of PS* forming the reduced species PS-, which then reduces the WRC to return to its original state before repeating

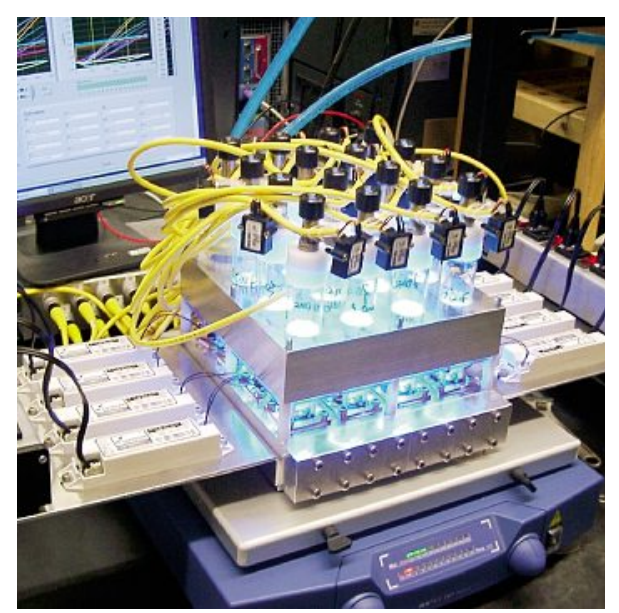

Fig. 1. 16-well photoreactor with bottom illumination (460 nm, $500 \pm 50 \mathrm{~mW}$ ), real-time analysis of gas evolution, and temperaturecontrolled reaction block.

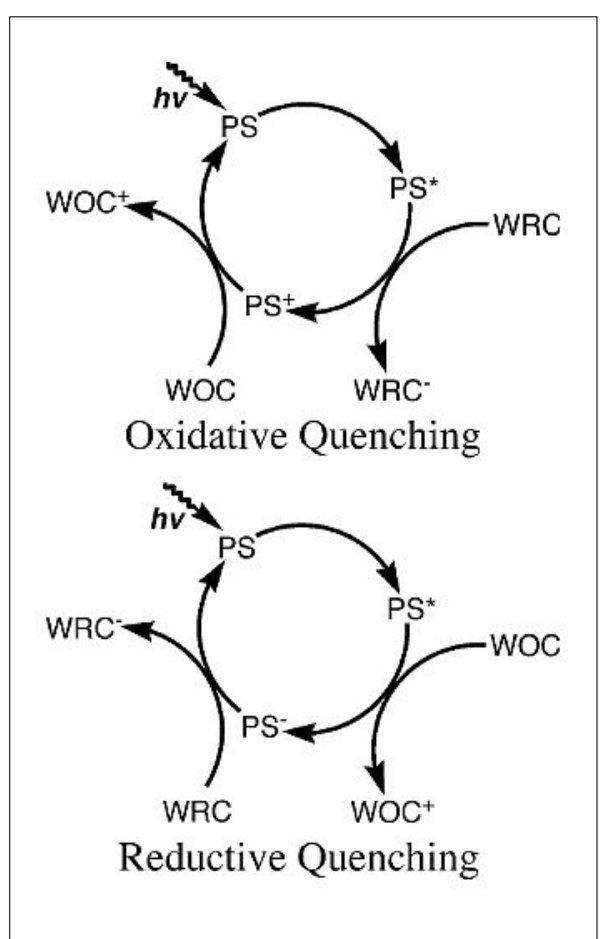

Fig. 2. Simplified schematic representation of two different pathways for photocatalytic water splitting. Top - oxidative quenching pathway in which excited photosensitizer, PS ${ }^{*}$, donates an electron to the water reduction catalyst, WRC, to produce $\mathrm{PS}^{+}$; Bottom - reductive quenching pathway in which PS* removes an electron from water oxidation catalyst, WOC, to produce PS-. The oxidized WOC and reduced WRC will then go on to oxidize and reduce water to produce $\mathrm{O}_{2}$ and $\mathrm{H}_{2}$, respectively.

the cycle. In the oxidative quenching pathway, the WRC is responsible for quenching the excited state through an electron transfer from the HSOMO of PS* to form the oxidized species $\mathrm{PS}^{+}$, which then is reduced by the WOC to return to its original state. In terms of relative energy, $\mathrm{PS}^{-}$is more strongly reducing than $\mathrm{PS}^{*}$, and $\mathrm{PS}^{+}$is more strongly oxidizing than PS*. Thus, the mechanisms by which the PS is quenched will determine the energy available to drive the catalytic processes. For this reason, it is important to be able to control the reaction pathway and energy levels of the PS molecules through ligand modification.

Most early work in the field focused on tris-(2,2'-bipyridine)-ruthenium(II), $\left[\mathrm{Ru}(\mathrm{bpy})_{3}\right]^{2+}$, a widely studied complex with a strong metal to ligand charge transfer (MLCT) absorption in the visible spectrum, long triplet excited state lifetimes, and stable one-electron redox products. However, tuning the HSOMO of $\left[\mathrm{Ru}(\mathrm{bpy})_{3}\right]^{2+*}$ is limited because of a low lying, anti-bonding metalcentered triplet ( $\left.{ }^{3} \mathrm{MC}\right)$ state that is thermally populated at room temperature leading to rapid non-radiative decay and PS degradation. ${ }^{[7]}$ Cyclometalated iridium(III) complexes, such as bis-(2-phenylpyridine)-(2,2'bipyridine)-iridium(III), $\quad\left[\operatorname{Ir}(\text { ppy })_{2}(\mathrm{bpy})\right]^{+}$, 
have greater ligand-field stabilization energy and strong field ligands that raise the energy of the ${ }^{3} \mathrm{MC}$ state to make it less accessible, allowing broader tuning capabilities through ligand modification. ${ }^{[8]}$

The cyclometalated iridium(III) compounds of the general form $\left[\operatorname{Ir}\left(\mathrm{C}^{\wedge} \mathrm{N}\right)_{2}\left(\mathrm{~N}^{\wedge} \mathrm{N}\right)\right]^{+}$ have two principle transitions: i) MLCT d- $\pi^{*}$ transitions linked to the neutral ancillary ligand (e.g. diimines, diphosphines, diones) and ii) ligand-centered transitions involving a $\pi-\pi *$ transition on the cyclometalating ligand (e.g. ppy, phenylpyrazole). Strong spin-orbit coupling from iridium(III) allows rapid intersystem crossing to energetically similar excited triplet states $\left(\mathrm{T}_{1}\right)$ that form an emissive mixed $\mathrm{T}_{1}$ state. ${ }^{[9]}$ The energy of this state, the HSOMO, can be controlled through simple chemical modifications of the ligand architecture that change the symmetry and inductive influence.

The Bernhard group first studied cyclometallated Ir(III) complexes for applications in OLED devices. ${ }^{[10]}$ Subsequently, the development of parallel synthesis and high-throughput screening techniques have enabled the rapid study of the effects of multiple structural modifications in tandem. ${ }^{[6]}$ The heteroleptic complexes are synthesized in high yield through two steps by preparation of tetrakis- $\left(\mathrm{C}^{\wedge} \mathrm{N}\right)-\mu$-(dichloro)diiridium(III) complexes using various cyclometalating ligands $\left(\mathrm{C}^{\wedge} \mathrm{N}\right)$ followed by dimer cleavage with the neutral ligands $\left(\mathrm{N}^{\wedge} \mathrm{N}\right)$. These methods yielded a series of complexes with a diverse range of properties, as shown in the color diversity of Fig. 3 and the wide range of ground state and excited state redox potentials in the Table.

This research showed that by separately substituting the $\mathrm{C}^{\wedge} \mathrm{N}$ and $\mathrm{N}^{\wedge} \mathrm{N}$ ligands with electron-withdrawing groups (e.g. fluoro, trifluoromethyl) and electron donating groups (e.g. tert-butyl, methoxy), it is possible to separately control the energy of the LSOMO and HSOMO. Additionally, the

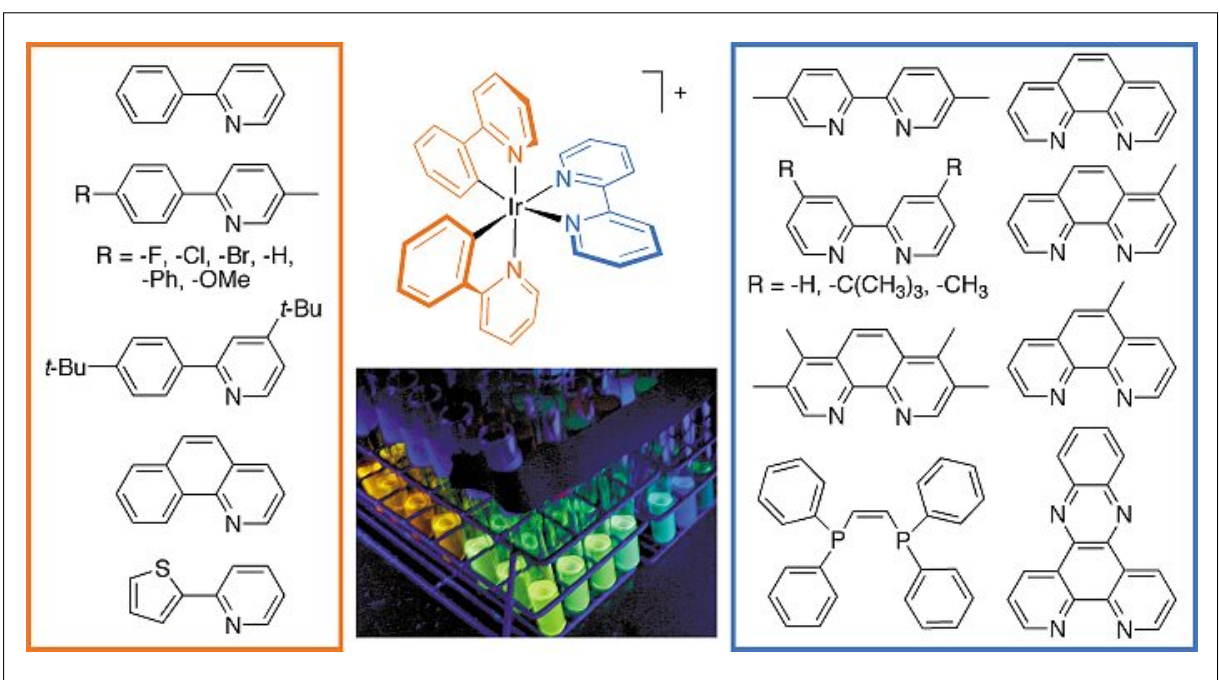

Fig. 3. Combinatorial library of cyclometallated iridium(III) complexes of the general form $\left[\operatorname{lr}\left(\mathrm{C}^{\wedge} \mathrm{N}\right)_{2}\left(\mathrm{~N}^{\wedge} \mathrm{N}\right)\right]^{+}$using ten cyclometallating ligands $\left(\mathrm{C}^{\wedge} \mathrm{N}\right.$, red box $)$ and ten neutral ligands $\left(\mathrm{N}^{\wedge} \mathrm{N}\right.$, blue box). The color versatility is demonstrated by the luminescence of the combinatorial matrix.

improved understanding of structure-property relationships allowed the use of DFT calculations to model orbital configurations, which has proven to be an excellent method for the prediction of excited state energies. ${ }^{[6]}$ This work demonstrates the capability to quickly design and synthesize an Ir(III) PS to drive a catalytic system using light energy if given a set of energetic requirements.

\section{Efficient Water Reduction Systems}

Historical systems for photocatalytic water reduction (Eqn. (3)) employed $\left[\mathrm{Ru}(\mathrm{bpy})_{3}\right]^{2+}$ as the PS with a sacrificial reductant (SR) e.g. a tertiary amine, an electron relay (ER) e.g. methyl viologen, and a heterogeneous catalyst e.g. Pt colloid for proton reduction. ${ }^{[11]}$ Heterogeneous systems depend on many parameters that are difficult to control, and their potential application in a complete water splitting system is limited because most heterogeneous catalysts, such as colloidal $\mathrm{Pt}$, promote the recombination of the $\mathrm{O}_{2}$ and $\mathrm{H}_{2}$ products. Thus, the development of efficient homogeneous photocatalytic systems for water reduction is of considerable importance to advance the science of artificial photosynthesis.

With the extensive range of properties demonstrated by the series of cyclometallated iridium(III) complexes synthesized in the Bernhard lab, they are perfectly suited as the PS in photosynthetic schemes where it is important to tune the energy levels so that they match those of the other components in the system. For several decades it has been known that $\left[\mathrm{Co}(\mathrm{bpy})_{3}\right]^{2+}$ was capable of serving in the capacity of the WRC, storing reducing equivalents and reducing protons to form $\mathrm{H}_{2}$ without the need for an additional ER. ${ }^{[12]}$ Utilizing the high-throughput LED photoreactor, the classical Ru-PSs and a se-

Table. The emission energy $\left(\lambda_{\text {emission }}\right)$, quantum yield of luminescence $\left(\Phi_{\mathrm{ph}}\right)$, excited state lifetime $(\tau)$, ground state reduction $\left(E^{0^{\prime}} \mathrm{PS} / \mathrm{PS}-\right)$ and oxidation $\left(E^{0^{\prime}} \mathrm{PS} / \mathrm{PS}^{+}\right)$potentials, and excited state reduction ( $\left.\left.E^{0^{\prime}{ }^{*} \mathrm{PS} / \mathrm{PS}}\right)^{-}\right)$and oxidation potentials ( $\left.E^{0^{\prime}} \mathrm{PS} / \mathrm{PS}^{+}\right)$of a family of Ir(III) photosensitizers (PS).

\begin{tabular}{|c|c|c|c|c|c|c|c|c|c|}
\hline photosensitizer ${ }^{a, b}$ & $\begin{array}{l}\lambda_{\text {emission }} \\
{[\mathrm{eV}]}\end{array}$ & $\begin{array}{l}\Phi_{\mathrm{ph}}{ }^{c} \\
{[\%]}\end{array}$ & $\begin{array}{l}\tau \\
{[\mu \mathrm{s}]}\end{array}$ & $\begin{array}{l}E^{0^{\prime}} \mathrm{PS} / \mathrm{PS}^{+d} \\
\text { [V vs. SCE] }\end{array}$ & $\begin{array}{l}\Delta E_{\mathrm{p}} \\
{[\mathrm{mV}]}\end{array}$ & $\begin{array}{l}E^{0^{\prime}} \mathrm{PS} / \mathrm{PS}^{-d} \\
{[\mathrm{~V} \text { vs. SCE] }}\end{array}$ & $\begin{array}{l}\Delta E_{\mathrm{p}} \\
{[\mathrm{mV}]}\end{array}$ & $\begin{array}{l}E^{0^{*}}{ }^{*} \mathrm{PS} / \mathrm{PS}{ }^{+e} \\
\text { [V vs. SCE] }\end{array}$ & $\begin{array}{l}E^{0 * *} \mathrm{PS} / \mathrm{PS}^{-}{ }^{-} \\
\text {[V vs. SCE] }\end{array}$ \\
\hline $\operatorname{Ir}(\mathrm{ppy})_{2}(\mathrm{bpy})^{+}$ & 2.10 & 6.22 & 0.269 & +1.25 & 65 & -1.42 & 70 & -0.85 & +0.68 \\
\hline $\operatorname{Ir}(p p y)_{2}(d t b b p y)^{+}$ & 2.17 & 17.2 & 0.621 & +1.21 & 65 & -1.51 & 65 & -0.96 & +0.66 \\
\hline $\operatorname{Ir}(\mathrm{F}-\mathrm{mppy})_{2}(\text { phen })^{+}$ & 2.22 & 33.1 & 1.64 & +1.36 & 60 & -1.39 & 80 & -0.86 & +0.83 \\
\hline $\operatorname{Ir}(F-m p p y)_{2}(d t b b p y)^{+}$ & 2.27 & 26.3 & 1.22 & +1.33 & 85 & -1.50 & 70 & -0.94 & +0.77 \\
\hline $\operatorname{Ir}(\mathrm{dF}-\mathrm{mppy})_{2}(\mathrm{dtbbpy})^{+}$ & 2.41 & 54.1 & 1.43 & +1.49 & 75 & -1.44 & 70 & -0.92 & +0.97 \\
\hline $\operatorname{Ir}\left(\mathrm{dF}-\mathrm{CF}_{3} \mathrm{ppy}\right)_{2}(\mathrm{dtbbpy})^{+}$ & 2.58 & 68 & 2.3 & +1.69 & 105 & -1.37 & 70 & -0.89 & +1.21 \\
\hline
\end{tabular}

${ }^{a} \mathrm{PF}_{6}$ - counterion; ${ }^{b}$ ppy is 2-phenylpyridine, fmppy is 2-(4-fluorophenyl)-5-methylpyridine, dfmppy is 2-(2,4-difluorophenyl)-5-methylpyridine, dfCF $_{3}$ ppy is 2-(2,4-difluorophenyl)-5-trifluoromethylpyridine, bpy is 2,2'-bipyridine, dtbbpy is 4,4'-di-tert-butylbpy, phen is 1,10-phenanthroline; ${ }^{c}\left[\mathrm{Ru}(\mathrm{bpy})_{3}\right]\left(\mathrm{PF}_{6}\right)_{2}$ used as reference $\left(\Phi_{\mathrm{ph}} 6.2 \%\right)$; ${ }^{d}$ Cyclic voltammetry was carried out at $100 \mathrm{mV} / \mathrm{s}$ in $0.1 \mathrm{M} \mathrm{TBAH} / \mathrm{ACN}$ with a $1 \mathrm{~mm}{ }^{2} \mathrm{Pt}$ disk electrode, coiled Pt wire supporting electrode, and $\mathrm{Ag}$ wire pseudo-reference electrode. Ferrocene was used as an internal standard (0.37 $\mathrm{V}$ vs SCE); 'Estimated from Hess' Law using the $\lambda$ and ground state redox potentials. 
ries of heteroleptic $\operatorname{Ir}($ III) complexes were evaluated in systems utilizing $\left[\mathrm{Co}(\mathrm{bpy})_{3}\right]^{2+}$ as the WRC and triethanolamine (TEOA) as the SR. ${ }^{[13]}$ The Ir-PS was proven superior to the classical Ru-PS, which was attributed to an alternative catalytic mechanism providing stronger reducing conditions in the case of the Ir-PS (see discussion in Section 4 and the relative redox potential of PS* and PS $^{-}$in the Table). $\left[\mathrm{Ru}(\mathrm{bpy})_{3}\right]^{2+}$ cannot be quenched reductively by TEOA and must operate exclusively by an oxidative quenching pathway, while Ir-PSs can be reductively quenched by the SR, presumably due to delocalization of some of the LSOMO density onto the peripheral ligands. ${ }^{[14]}$ Under the conditions employed, reductive quenching was the favored pathway for the Ir-Co system, meaning the highly reducing species $\mathrm{PS}^{-}$provides the reducing equivalents to the WRC.

In the Ir-Co system, the catalytic activity quickly deteriorated, presumably due to catalyst degradation. The reductive quenching mechanism for the Ir-PS enabled construction of a simplified heterogeneous system consisting of only Ir-PS, TEOA, and Pt colloid, without the need for an additional ER for excited state quenching as in the classical heterogeneous systems. Using real-time pressure analysis to monitor $\mathrm{H}_{2}$ evolution for the simplified reaction, it was determined that the catalytic activity was decaying by first- or pseudo-first-order kinetics. Mass spectroscopic analysis of samples from the reaction media at selected time points during the reaction demonstrated that the loss of catalytic activity was due to ligand labilization and subsequent displacement by solvent molecules, in this instance the acetonitrile used as a co-solvent with water. ${ }^{[14]}$ This simplified system allowed for the characterization of the PS degradation products that might otherwise have been obscured in more complex systems.

Numerous efforts to improve the performance of the Ir-Co systems demonstrated the need for an improved WRC, for which $\left[\mathrm{Rh}(\mathrm{bpy})_{3}\right]^{3+}$ was an ideal candidate because it accumulates two electrons at a suitable potential for water reduction and is known to form hydrides. Previous attempts to implement $\left[\mathrm{Rh}(\mathrm{bpy})_{3}\right]^{3+}$ as the WRC with $\left[\mathrm{Ru}(\mathrm{bpy})_{3}\right]^{2+}$ and TEOA initiated the formation of $\left[\mathrm{Rh}(\mathrm{bpy})_{2}\right]^{+}$and free bpy with only minimal $\mathrm{H}_{2}$ production, proving that the $\left[\mathrm{Rh}(\mathrm{bpy})_{2}\right]^{+}$ species was not the active catalytic state. ${ }^{[15]}$ Mulazzani et al. hypothesized that $\mathrm{Rh}$ (II)hydrides might be the immediate precursor to $\mathrm{H}_{2}$ formation in radiolytic studies.[16] The reductive quenching mechanism of the Ir-PS provides a highly reducing species, $\mathrm{PS}^{-}\left(E^{0^{\prime}} \approx-1.4 \mathrm{~V} v s\right.$. SCE), that would allow the $\left[\mathrm{Rh}(\mathrm{bpy})_{3}\right]^{3+}$ to be reduced three times to form a $\mathrm{Rh}(0)$ species that might then react with water to form the hypothesized active state.
Indeed, the Ir-PS allowed for the successful implementation of the Rh-WRC in the photocatalytic water reduction system, which proved much more active and robust than the previous Ir-Co system. Synthetic modification and high-throughput catalyst screening identified an optimal catalyst combination of $\left[\operatorname{Ir}(\mathrm{fmppy})_{2}(\mathrm{dtbbpy})\right]\left(\mathrm{PF}_{6}\right)$ and $\left[\mathrm{Rh}(\mathrm{dtbbpy})_{3}\right]\left(\mathrm{PF}_{6}\right)_{3}$ (where fmppy is 4-fluorophenyl)-5-methyl-pyridine and dtbbpy is 4,4'-di-tert-butyl-2,2'-bipyridine). The use of weakly coordinating co-solvents (e.g. DMF, THF) and the systematic optimization of the reaction conditions led to more than two orders of magnitude improvement over the original system. The optimized system currently achieves more than 5000 turnovers for the PS and WRC with quantum yields of greater than $34 \%$ and turnover frequencies (TOF) greater than $500 \mathrm{hr}^{-1}$. ${ }^{[17]}$

With any homogeneous system, care must be taken to ensure that the catalytic activity originates from an actual molecular species and not a colloidal metal formed through complex decomposition. It has recently been proven in two separate instances that Pt(II) or Pd(II) 'molecular' catalysts were actually decomposing to form colloids, which were the active catalyst species. ${ }^{[18]}$ In the Ir-Rh system, the generation of a rhodium colloid was firmly ruled out through a series of control and poisoning experiments that ensure a true homogeneous system. The exact mechanism by which the WRC operates is still unknown, although future work will reveal the details. The Ir-Rh system shows real progress towards an efficient, robust, homogeneous photocatalytic system for the reduction of water.

\section{Robust Water Oxidation Catalysts}

Although reasonable progress has been made with systems for photocatalytic water reduction, the same cannot be said for the more complex oxidative half reaction (Eqn. (2)). In contrast to the two-electron process for water reduction, the challenge of water oxidation lies in the complexity of orchestrating four simultaneous PCET to obtain only the desired product, $\mathrm{O}_{2}$. This process has yet to be driven by visible light, so researchers generally develop WOCs capable of catalyzing this complex reaction by replacing the PS with an irreversible sacrificial oxidant such as ceric ion or persulfate.

The WOCs generally fall into two categories: heterogeous metal oxide electrodes and colloids based on manganese, iron, cobalt, ruthenium, and iridium; $; 19]$ and molecular catalysts, including polyoxometalates that mimic the tetramanganese core of photosystem $\mathrm{II}^{[20]}$ or simpler binuclear transition metal complexes. [21] Meyer and coworkers pioneered the latter class of complexes in the early 1980s with the $\mu$-oxo-bridged, aquo bis-diimine ruthenium dimer known as the blue dimer (Fig. 4).[21a] The blue dimer has long been the gold standard for water oxidation with a TOF of nearly $250 \mathrm{hr}^{-1}$. Evidence suggests that the mechanism involves water attack of a ruthenium-oxo species to form a hydroperoxo-intermediate, which then evolves oxygen following PCET and reductive elimination. ${ }^{[22]}$ Recently, Thummel and Zong reported a diruthenium complex using a rigid ligand architecture to lock the metalcenters in an optimal spatial configuration (Fig. 4). This WOC achieves an even higher TOF than the blue dimer and more than an order of magnitude improvement in catalyst turnovers. ${ }^{[21 a, c]}$ Importantly, the synthetic modification of the ligand architecture was shown to alter the oxidative potential of the Thummel complex by more than $600 \mathrm{mV}$, the first report of a tunable WOC.[23]

The ability to precisely control the electronic structure of WOCs through ligand modification, without substantially changing the catalyst functionality, is an indispensable tool when attempting to develop a photocatalytic water oxidation system. The Bernhard group has recently developed a cyclometallated iridium WOC (Fig. 4) that demonstrates the same capacity for redox tuning as the Thummel diruthenium complex. ${ }^{[24]}$ By synthetic modification of the 2-phenyl-pyridine ligand with electron withdrawing or donating substituents, the HOMO energy was tuned by more than $500 \mathrm{mV}$. The Ir-WOCs are very robust with more than 2800 turnovers, yet the TOFs are five times slower than the previous $\mathrm{Ru}$ WOC examples. The low TOF is probably due the monomeric catalyst forming some type of oxo-bridged dimer intermediate in a diffusion-limited process. This might be overcome by locking the two reactive iridium centers in place with a cage ligand similar to that used by Thummel. In the meantime, this Ir-WOC shows great promise as a component for the development of a visible-light water oxidation process for several reasons: it has a simple design for ease of synthesis and study, the cyclometalating ligand makes the catalyst robust, it is water soluble through a wide $\mathrm{pH}$ range, and its HOMO is highly tunable for energy matching with the LSOMO of the PS.[24]

\section{Challenges Moving Forward}

Many challenges exist as we move forward towards a complete homogeneous water splitting system. Once compatible PS, WOC, and WRC components are found, the electron transfer processes must be perfected for optimal performance. The catalyst systems need to have efficient quenching of the photo-excited PS complex and a long lifetime for the subsequent charge- 


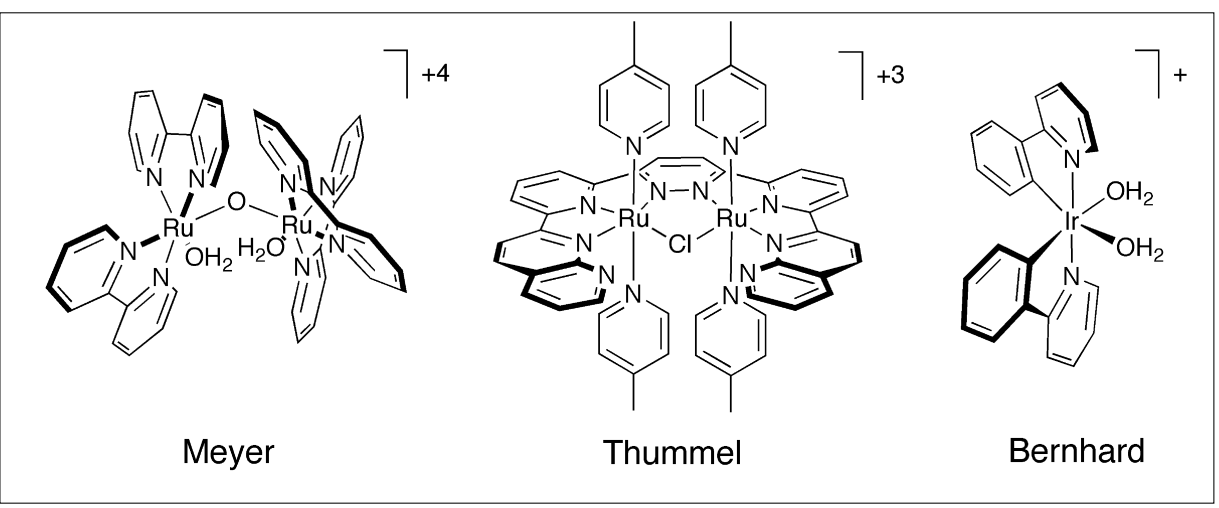

Fig. 4. Molecular water oxidation catalysts from the groups of Meyer, Thummel, and Bernhard.

separated state. The natural photosynthetic machinery fulfills these requirements by precise control of spatial organization, electronic coupling, and relative redox energies of the adjacent components, giving the systems directional charge-transfer character. To accomplish these same feats in the laboratory, the components can be linked using multidentate bridging ligands that orchestrate electron transfer by providing optimal spatial separation and electronic coupling. However, to put this into practice while handling multiple protons and electrons will be a monumental accomplishment.

One of the greatest obstacles for solar energy conversion is to design systems that can efficiently convert a large portion of the solar spectrum to usable energy. For the electron transfer processes between the PS and catalysts to occur at reasonable rates the reactions must be exothermic by $0.3-0.4 \mathrm{eV}$ each. Considering the electron transfers and excited state relaxation, it is reasonable to assume that almost twice the theoretical energy will be required, meaning that only light below $504 \mathrm{~nm}$ wavelength have sufficient energy to run a complete water splitting system and only $24 \%$ of the solar power is available. However, due to factors such as the internal conversion to heat during downhill electron transfer, incomplete light absorption, non-ideal quantum yields, and losses during $\mathrm{H}_{2} / \mathrm{O}_{2}$ separation and collection, the realistic overall efficiency is limited to $10 \%$. To raise this maximum theoretical efficiency, tandem cells or multiphoton schemes must be developed.[25] This fundamental limitation magnifies the need to overcome the many challenges that researchers face when attempting to improve the various light absorption and electron transfer processes.

\section{Conclusion}

This review outlines the various coordinated efforts of the Bernhard research group to make rapid progress towards mo- lecular catalytic systems for the visible-light induced splitting of water. Combinatorial synthesis and high-throughput screening techniques enabled the development of a series of photosensitizers with a wide range of photophysical and electrochemical properties. Parallel evaluation of the iridium(III) photosensitizers in photocatalytic water reduction systems utilizing cobalt-, platinum-, or rhodium-based water reduction catalysts resulted in systems that exhibited more than 5000 turnovers with quantum yields of $34 \%$ and turnover frequencies of $500 \mathrm{hr}^{-1}$. For the complementary water oxidation system, the catalysts based on cyclometallated iridium complexes are robust and tunable, which allows for the rapid study of water oxidation reactions through targeted ligand modification. While the present systems for photocatalytic water reduction and the oxidation of water are state of the art, significant improvements are required to realize the dream of an efficient system for solar energy conversion. The insight provided from the empirical results will help guide future work towards a complete water splitting system.

Received: June 5, 2009

[1] 'International Energy Outlook 2008', Energy Information Administration, U.S. Department of Energy, Washington, DC, 2008; www.eia.doe. gov/oiaf/ieo/index.html.

[2] 'Climate Change 2007: The Physical Science Basis', Intergovernmental Panel on Climate Change, World Meteorological Organization and United Nations Environment Programme, Paris, France, 2007; www.ipcc.ch/ipccreports/ar4-wg1. htm.

[3] N. S. Lewis, D. G. Nocera, Proc. Natl. Acad. Sci. 2006, 103, 15729.

[4] 'Basic Research Needs for Solar Energy Utilization', U.S. Department of Energy, Washington, DC, 2005; www.er.doe.gov/bes/reports/abstracts. html\#SEU.

[5] a) A. J. Bard, M. A. Fox, Acc. Chem. Res. 1995, 28, 141; b) A. Currao, Chimia 2007, 61, 815; c) R. van de Krol, Y. Liang, J. Schoonman, J. Mater. Chem. 2008, 18, 2311.

[6] a) M. S. Lowry, W. R. Hudson, R. A. Pascal, S. Bernhard, J. Am. Chem. Soc. 2004, 126, 14129; b) M. S. Lowry, J. I. Goldsmith, J. D. Slinker, R. Rohl, R. A. Pascal, G. G. Malliaras, S. Bernhard, Chem. Mater. 2005, 17, 5712.
[7] K. Kalyanasundaram, 'Photochemistry of Polypyridine and Porphyrin Complexes' Academic Press, New York, 2002.

[8] R. J. Watts, J. Van Houten, J. Am. Chem. Soc. 1974, 96, 4334

[9] a) M. G. Colombo, A. Hauser, H. U. Güdel, Top. Curr. Chem. 1994, 171, 143; b) P. J. Hay, J. Phys. Chem. A 2002, 106, 1634.

[10] a) J. D. Slinker, A. A. Gorodetsky, M. S. Lowry, J. Wang, S. Parker, R. Rohl, S. Bernhard, G. G. Malliaras, J. Am. Chem. Soc. 2004, 126, 2763; b) S. T. Parker, J. D. Slinker, M. S. Lowry, M. P. Cox, S. Bernhard, G. G. Malliaras, Chem. Mat. 2005, 17, 3187; c) J. D. Slinker, C. Y. Koh, G. G. Malliaras, M. S. Lowry, S. Bernhard, Appl. Phys. Lett. 2005, 86, 173506; d) J. D. Slinker, J. Rivnay, J. S. Moskowitz, J. B. Parker, S. Bernhard, H. D. Abruna, G. G. Malliaras, J. Mater. Chem. 2007, 17, 2976; e) E. Zysman-Colman, J. D. Slinker, J. B. Parker, G. G. Malliaras, S. Bernhard, Chem. Mat. 2008, 20, 388.

[11] a) A. Moradpour, E. Amouyal, P. Keller, H. Kagan, Nouv. J. Chim. 1978, 2, 547; b) M. Kirch, J. Lehn, J. Sauvage, Helv. Chim. Acta 1979, 62, 1345; c) K. Kalyanasundaram, J. Kiwi, M. Gratzel, Helv. Chim. Acta. 1978, 61, 2720; d) G. M. Brown, B. S. Brunschwig, C. Creutz, J. F. Endicott, N. Sutin, J. Am. Chem. Soc. 1979, 101, 1298.

[12] a) C. V. Krishnan, B. S. Brunschwig, C. Creutz, N Sutin, J. Am. Chem. Soc. 1985, 107, 2005; b) K. J. Brewer, W. R. Murphy, K. J. Moore, E. C. Eberle, J. D. Petersen, Inorg. Chem. 1986, 25, 2470.

[13] J. I. Goldsmith, W. R. Hudson, M. S. Lowry, T. H. Anderson, S. Bernhard, J. Am. Chem. Soc. 2005, 127,7502 .

[14] L. L. Tinker, N. D. McDaniel, P. N. Curtin, C. K. Smith, M. J. Ireland, S. Bernhard, Chem. Eur. J. 2007, 13, 8726 .

[15] a) M. Kirch, J. Lehn, J. Sauvage, Helv. Chim. Acta 1979, 62, 1345; b) S. Chan, M. Chou, C. Creutz, T. Matsubara, N. Sutin, J. Am. Chem. Soc. 1981, 103, 369.

[16] Q. G. Mulazzani, M. Venturi, M. Z. Hoffman, J. Phys. Chem. 1982, 86, 242.

[17] E. D. Cline, S. E. Adamson, S. Bernhard, Inorg. Chem. 2008, 47, 10378.

[18] a) P. Lei, M. Hedlund, R. Lomoth, H. Rensmo, O. Johansson, L. Hammarstrom, J. Am. Chem. Soc. 2008, 130, 26; b) P. Du, J. Schneider, F. Li, W. Zhao, U. Patel, F. N. Castellano, R. Eisenberg, J. Am. Chem. Soc. 2008, 130, 5056.

[19] a) G. L. Elizarova, G. M. Zhidomirov, V. N. Parmon, Catal. Today 2000, 58, 71; b) A. G. Dokoutchaev, F. Abdelrazzaq, M. E. Thompson, J. Willson, C. Chang, A. Bocarsly, Chem. Mat. 2002, 14, 3343; c) N. D. Morris, T. E. Mallouk, J. Am. Chem. Soc. 2002, 124, 11114.

[20] a) W. Ruettinger, M. Yagi, K. Wolf, S. Bernasek, G. C. Dismukes, J. Am. Chem. Soc. 2000, 122, 10353; b) A. Sartorel, M. Carraro, G. Scorrano, R. D. Zorzi, S. Geremia, N. D. McDaniel, S. Bernhard, M. Bonchio, J. Am. Chem. Soc. 2008 130, 5006.

[21] a) S. W. Gersten, G. J. Samuels, T. J. Meyer, J. Am. Chem. Soc. 1982, 104, 4029; b) M. Yagi, Y. Osawa, N. Sukegawa, M. Kaneko, Langmuir 1999, 15, 7406; c) R. Zong, R. P. Thummel, J. Am. Chem. Soc. 2005, 127, 12802.

[22] a) C. W. Chronister, R. A. Binstead, J. Ni, T J. Meyer, Inorg. Chem. 1997, 36, 3814; b) R. A. Binstead, C. W. Chronister, J. Ni, C. M. Hartshorn, T. M. Meyer, J. Am. Chem. Soc. 2000 , 122, 8464; c) F. Liu, J. J. Concepcion, J. W. Jurss, T. Cardolaccia, J. L. Templeton, T. J. Meyer, Inorg. Chem. 2008, 47, 1727.

[23] Z. Deng, H. Tseng, R. Zong, D. Wang, R. Thummel, Inorg. Chem. 2008, 47, 1835.

[24] N. D. McDaniel, F. J. Coughlin, L. L. Tinker, S. Bernhard, J. Am. Chem. Soc. 2008, 130, 210.

[25] J. R. Bolton, S. J. Strickler, J. S. Connolly, Nature 1985, 316, 495. 